\title{
La OMS valida la eliminación de Cuba de la transmisión de madre a hijo del VIH y de la sífilis
}

\author{
Comunicado de prensa.
}

Disponible en: http://www.who.int/mediacentre/news/releases/2015/mtct-hiv-cuba/es/

30 de junio de 2015 / Ginebra / DC - Cuba se convirtió hoy en el primer país del mundo en recibir la validación por parte de la Organización Mundial de la Salud (OMS) de que ha eliminado la transmisión de madre a hijo del VIH y la sífilis.

"La eliminación de la transmisión de un virus es uno de los mayores logros posibles en la salud pública", dijo Margaret Chan, Directora General de la OMS. "Esta es una victoria importante en nuestra larga lucha contra el VIH y las infecciones de transmisión sexual, y un paso importante hacia una generación libre de sida", añadió.

"Esta es una celebración para Cuba y una celebración para los niños y familias de todo el mundo. Esto demuestra que el fin de la epidemia del sida es posible y esperamos que Cuba sea el primero de muchos países que vienen a buscar la validación de que han terminado sus epidemias entre los niños ", manifestó Michel Sidibé, Director Ejecutivo de ONUSIDA.

\section{El desafío}

Cada año, alrededor de 1,4 millones de mujeres viviendo con VIH quedan embarazadas en el mundo. Si no se tratan, tienen entre 15 y $45 \%$ de posibilidades de transmitir el virus a sus hijos durante el embarazo, el parto o la lactancia. Sin embargo, ese riesgo se reduce a poco más de $1 \%$ si se suministra antirretrovirales a las madres y los niños en las etapas en las que puede producirse la infección.

Desde 2009, el número de niños que nacen cada año con VIH se ha reducido a casi la mitad, al pasar de 400.000 a 240.000 en 2013. Pero será necesario redoblar los esfuerzos para alcanzar la meta mundial de que haya menos de 40.000 nuevas infecciones infantiles por año para 2015.
Casi 1 millón de embarazadas en todo el mundo se infectan con sífilis anualmente. Esto puede resultar en muerte fetal, muerte perinatal o en infecciones neonatales graves. Sin embargo, opciones simples y rentables de detección y tratamiento durante el embarazo, como la penicilina, pueden eliminar la mayoría de estas complicaciones.

\section{El logro de Cuba}

La OPS/OMS y sus socios trabajan con Cuba y otros países de las Américas desde 2010, en la implementación de una iniciativa para eliminar la transmisión de madre a hijo del VIH y la sífilis.

Como parte de la iniciativa regional, Cuba ha trabajado para asegurar el acceso temprano a la atención prenatal, a las pruebas para detectar el VIH y la sífilis tanto para las embarazadas como para sus parejas, para proveer el tratamiento para las mujeres que dan positivo y sus bebés, en la sustitución de la lactancia materna y la prevención del VIH y de la sífilis antes y durante el embarazo a través del uso de preservativos y otras medidas de prevención. Estos servicios se ofrecen como parte de un sistema de salud equitativo, accesible y universal en el que los programas de salud maternoinfantil se integran con los programas para el VIH y las infecciones de transmisión sexual.

"El éxito de Cuba demuestra que el acceso universal y la cobertura universal de salud son factibles y de hecho son la clave del éxito, incluso en contra de desafíos tan complejos como el VIH", afirmó hoy Carissa F. Etienne, Directora de la Organización Panamericana de la Salud (OPS), Oficina Regional para las Américas de la OMS, en una conferencia de prensa celebrada en la OPS, para anunciar este logro. 


\section{Esfuerzos globales para detener la transmisión madre a hijo de VIH y sífilis}

En los últimos años se han hecho esfuerzos importantes en todo el mundo para asegurar que las mujeres accedan al tratamiento que necesitan para mantenerse bien y para que sus hijos estén libres de VIH y sífilis. Un grupo de países en otras regiones también están a punto de eliminar la transmisión de madre a hijo de ambas enfermedades.

En 2007, la OMS lanzó la guía Eliminación mundial de la sífilis congénita: fundamentos y estrategia para la acción. La estrategia busca aumentar el acceso global a las pruebas de sífilis y al tratamiento de las embarazadas. Para 2014, más de 40 países estaban haciendo la prueba por sífilis al $95 \%$ o más de mujeres embarazadas en el control prenatal. Pero aunque se han hecho progresos, muchos países aún deben priorizar la prevención y el tratamiento de la transmisión de madre a hijo de la sífilis. En 2012, la sífilis afectó unos 360.000 embarazos, a través de muerte fetal, neonatal, bebes prematuros y bebes infectados.

En 2011, ONUSIDA con la OMS y otros socios lanzaron un plan global con el objetivo de eliminar para 2015 las nuevas infecciones de VIH entre los niños y mantener a sus madres vivas. Este movimiento global ha impulsado el liderazgo político, la innovación y la participación de las comunidades para asegurar que los niños permanezcan libres de $\mathrm{VIH}$ y que sus madres permanecen vivos y bien.

Entre 2009 y 2013, la proporción de mujeres embarazadas viviendo con VIH en países de bajos y medianos ingresos que reciben medicinas antirretrovirales efectivas para prevenir la transmisión del virus a sus hijos se duplicó. Eso significa que en esos países, siete de cada 10 mujeres embarazadas viviendo con $\mathrm{VIH}$ en la actualidad reciben medicinas antirretrovirales eficaces para prevenir la transmisión del virus a sus hijos. Entre los 22 países que concentran el $90 \%$ de las nuevas infecciones de VIH, ocho ya han reducido nuevas infecciones de VIH entre los niños por más del $50 \%$ desde 2009, según datos de 2013, y otros cuatro están cerca de esta marca.

\section{Proceso de validación de la OMS}

En 2014, la OMS y sus socios claves publicaron los Lineamientos sobre los procesos y criterios mundiales para la validación de la eliminación de la transmisión madre a hijo del VIH y la sífilis, que explica el proceso de validación y los diferentes indicadores que los países necesitan alcanzar.

Como el tratamiento para la prevención de la transmisión de madre a hijo no es $100 \%$ efectiva, la eliminación de la transmisión se define como la reducción de la transmisión hasta un nivel tan bajo que ya no constituye un problema de salud pública.

Una misión de expertos internacionales convocados por la OPS/OMS visitó Cuba en marzo de 2015 para validar los progresos realizados hacia la eliminación de la transmisión madre a hijo del VIH y la sífilis. Durante la visita de cinco días, los integrantes de la misión visitaron centros de salud, laboratorios y oficinas gubernamentales a lo largo de la isla, entrevistaron a funcionarios de la salud y a otros actores claves. La misión incluyó expertos de Argentina, Bahamas, Brasil, Colombia, Italia, Japón, Nicaragua, Surinam, Estados Unidos y Zambia.

El proceso de validación prestó particular atención a la defensa de los derechos humanos, para asegurar que los servicios que se prestaban estuvieran libres de coerción y de acuerdo a los principios de derechos humanos.

\section{Nota a los editores:}

Los indicadores requeridos para la validación incluyen:

\section{VIH}

Indicadores de impacto - se deben alcanzar por al menos 1 año

- Nuevas infecciones pediátricas de VIH por transmisión madre a hijo del virus son menos de 50 casos por 100.000 nacidos vivos; $y$

- la tasa de transmisión de madre a hijo de VIH es menor al $5 \%$ en poblaciones que están recibiendo leche materna o menos de $2 \%$ en poblaciones alimentadas con leche maternizada.

Indicadores de proceso - se deben alcanzar por al menos 2 años

- Más del 95\% de las mujeres embarazadas, tanto las que saben como las que no saben de su estatus de VIH, deben recibir al menos una visita prenatal

- Más del 95\% de las mujeres embarazadas saben su estatus de VIH

- Más del 95\% de las mujeres con VIH positivo reciben tratamiento antirretroviral

\section{Sífilis}

Indicadores de impacto - se deben alcanzar por al menos 1 año

- Tasa de transmisión madre a hijo de sífilis es menor a los 50 casos por 100.000 nacidos vivos

Indicadores de proceso- se deben alcanzar por al menos 2 años

- Más del 95\% de las mujeres embarazadas recibieron al menos una visita prenatal 
- Más del 95\% de las mujeres embarazadas se hicieron la prueba por sífilis

- Más del 95\% de las mujeres embarazadas con sífilis reciben tratamiento

El término "validación" se usa para dar fe que un país ha alcanzado los indicadores de manera exitosa (las metas internacionales establecidas para la validación) para eliminar la transmisión de madre a hijo del VIH y/o sífilis en un punto específico del tiempo, pero los países deben mantener los programas en curso.

En 2013, sólo dos bebés nacieron con VIH en Cuba, y sólo tres nacieron con sífilis congénita. 